\title{
Antioxidant Treatment Inhibits the Development of Intimal Thickening after Balloon Injury of the Aorta in Hypercholesterolemic Rabbits
}

\author{
Anna Freyschuss, * Ann Stiko-Rahm, ${ }^{*}$ Jesper Swedenborg, ${ }^{5}$ Peter Henriksson, * \\ Ingemar Björkhem," Lars Berglund," and Jan Nilsson* \\ *Department of Medicine, Huddinge University Hospital, S-14186 Huddinge, Sweden; ${ }^{*}$ Department of Medicine \\ and King Gustaf Vth Research Institute, ${ }^{\S}$ Department of Surgery, Karolinska Hospital, S-10401 Stockholm; and "Department of Clinical \\ Chemistry, Huddinge University Hospital, Karolinska Institutet, S-14186 Huddinge, Sweden
}

\begin{abstract}
The effect of the antioxidant butylated hydroxytoluene (BHT) on the accumulation of intimal smooth muscle cells (SMC) and development of intimal thickening after balloon catheter injury of the aorta were studied in rabbits with dietary-induced hyperlipidemia. Two sets of New Zealand White rabbits (eight rabbits in each group) were fed either $0.25 \%$ cholesterol or $0.25 \%$ cholesterol/1\% BHT for a total of 6 wk. Serum lipid levels did not differ between the two groups. 3 wk after the start of the study, a balloon injury of the aorta was performed, after which the rabbits were kept on their respective diets for another 3 wk. After this period of time, the rabbits were killed and their aortas were investigated. The BHT-treated rabbits had only one fourth of the intimal thickness $(P<0.0001)$ and half the number of $\mathrm{SMC} / \mathrm{mm}$ intima $(P<0.001)$, as compared to the rabbits fed only cholesterol. There was also a lower number of macrophages in the BHT-treated group. T lymphocytes were present in the intima of cholesterol-fed rabbits, whereas no such cells could be identified in the BHT-fed animals. There were significantly lower levels of autooxidation products of cholesterol (7oxocholesterol, cholesterol-5,6-epoxide, and $7 \beta$-hydroxycholesterol) in the aortas of BHT-treated rabbits, $P<0.001$.

In conclusion, the antioxidant BHT effectively inhibited the accumulation of intimal SMC and the development of intimal thickening of the aorta in hypercholesterolemic rabbits after a balloon catheter-induced injury. These results indicate that antioxidants may modify intimal response to injury. (J. Clin. Invest. 1993. 91:1282-1288.) Key words: atherosclerosis • butylated hydroxytoluene - endothelial injury • hyperlipidemia • smooth muscle cells
\end{abstract}

\section{Introduction}

Several lines of evidence have suggested that oxidation of LDL could be an important initiating factor in the development of atherosclerotic lesions (1). Based on in vitro experiments demonstrating that macrophages have few receptors for native LDL but express abundant receptors for oxidatively modified LDL, it has been proposed that the formation of foam cells in athero-

Address correspondence to Anna Freyschuss, Department of Medicine, Huddinge University Hospital, S-14186 Huddinge, Sweden.

Received for publication 5 June 1992 and in revised form 13 October 1992.

J. Clin. Invest.

(C) The American Society for Clinical Investigation, Inc. $0021-9738 / 93 / 04 / 1282 / 07 \quad \$ 2.00$

Volume 91, April 1993, 1282-1288 sclerotic plaques is caused by uptake of oxidized LDL by intimal macrophages (1-3). This notion has been further supported by immunohistochemical studies demonstrating the presence of macrophages containing oxidized LDL in atherosclerotic lesions $(4,5)$. There is also in vitro evidence that oxidized LDL may influence the release of monocyte chemo-attractants from endothelial cells (6) and the ability of these cells to adhere mononuclear leukocytes $(7,8)$. Oxidized LDL also promotes differentiation of monocytes into macrophages (9) and activates $\mathrm{T}$ lymphocytes by a monocyte-dependent mechanism (10).

Considerable interest has focused on the possibility that oxidation of LDL may contribute to the intimal accumulation of smooth muscle cells (SMC) ${ }^{1}$, which is one of the major characteristics of human atherosclerosis $(11,12)$. In vitro, endothelial cells, SMC, and macrophages all have the capacity to produce PDGF, the major serum mitogen for cultured SMC (13-15). Expression of PDGF at both the gene and protein levels, has been found in atherosclerotic plaques, indicating that locally produced growth factors may be involved in the activation of intimal SMC proliferation (16-18). We have recently shown that oxidized LDL stimulates secretion of PDGF/A from human vascular SMC (19). However, others have demonstrated an inhibitory effect of oxidized LDL on PDGF release from macrophages (20) and the question whether lipoprotein oxidation results in increased release of growth factors from vascular cells in vivo remains controversial.

The hypothesis that oxidation of LDL plays an important role in atherogenesis has, however, been further substantiated by animal studies demonstrating that probucol, a lipid lowering drug with antioxidant properties, is a more potent inhibitor of formation of arterial lipid-rich lesions than other equally lipid lowering drugs $(21,22)$. Recently, we reported that the antioxidant butylated hydroxytoluene (BHT), in spite of increased serum lipid levels, inhibited the development of atherosclerosis in cholesterol-fed rabbits (23). In the present work, a modification of the BHT model has been used to evaluate the role of lipoprotein oxidation in the development of intimal hyperplasia. It is well known that mechanical injury of vascular tissue results in migration of SMC from the media into the intima, where cell replication and secretion of extracellular matrix components leads to the development of fibromuscular lesions. We report here that the antioxidant BHT effectively inhibits the accumulation of intimal SMC and the development of intimal thickenings after a balloon catheter-induced injury of the aorta in mildly hypercholesterolemic rabbits.

1. Abbreviations used in this paper: BHT, butylated hydroxytoluene; SMC, smooth muscle cells. 


\section{Methods}

Animals and treatments. 16 young male New Zealand White rabbits with an average weight of $3.4 \mathrm{~kg}(2.9-3.9 \mathrm{~kg})$ were housed individually under conditions of 12-h light/dark periods. Eight of the rabbits were fed standard rabbit pellets supplemented with $0.25 \%$ (wt/wt) cholesterol (Ewos Brood Stock Feed; Ewos AB, Södertälje, Sweden) for 6 wk and the remaining eight were fed the same diet with an additional supplement of $1 \%(w t / w t)$ BHT. Cholesterol and BHT were pelleted into the rabbit chow without the use of solubilizing vehicles.

After 3 wk of feeding, the rabbits were subjected to anesthesia intravenously (Mebumal Vet; Nordvacc, Stockholm, Sweden). Aortic endothelial injury was inflicted in the anaesthetized rabbits with a balloon catheter. A catheter was introduced into the aorta via one femoral artery to the aortic arch. The balloon was inflated by injection of air from a 20-ml syringe to achieve constant lateral wall pressure along the aorta during withdrawal of the catheter. The catheter was withdrawn with the balloon inflated three times. After the procedure, the femoral artery was ligated and the wound was sutured.

After the surgical procedure, the animals were kept on their respective diets for another $3 \mathrm{wk}$. At the end of the study, the rabbits were killed by an intravenous overdose of fluanizone and phentanyl. In addition, a separate set of animals (four BHT/cholesterol-fed and four cholesterol-fed rabbits) were killed before intimal injury after 3 wk of feeding of the respective diets. The project was approved by the Animal Ethical Committee (Stockholm).

Analytical methods. Before the study, at the time of the traumatic balloon injury to the aorta and at the end of the study (i.e., at weeks 0 , 3 , and 6), blood samples were drawn from an ear vein of each rabbit. After centrifugation, the plasma samples were analyzed for cholesterol and triglycerides using standard enzymatic procedures (Boehringer Mannheim GmbH, Mannheim, Germany). Hyperlipidemic sera were diluted before the assay, and under the conditions used, there was a linear relation between photometric response and amount of serum cholesterol or triglycerides. The mean levels of plasma cholesterol were $1.19,6.28$, and $7.78 \mathrm{mM}$ in the cholesterol-fed animals, whereas the corresponding values for the cholesterol- and BHT-fed animals were $1.25,7.50$, and $11.31 \mathrm{mM}$.

Concentrations of 7-oxocholesterol, cholesterol $5 \alpha, 6 \beta$-epoxide, and $7 \beta$-hydroxycholesterol were measured by isotope dilution mass spectrometry (24). Briefly, the aortic tissue was immediately frozen in liquid nitrogen, pulverized, and extracted with methanol/chloroform 1:2 ( $\mathrm{vol} / \mathrm{vol}$ ). After evaporation of the solvent, the samples were dissolved in $0.5 \mathrm{ml}$ chloroform and fractionated (Bond-Elut $\mathrm{NH}_{2}$ column; Varian Sample Preparation Products, Harbor City, CA) as described (25). After collection of the neutral lipid fraction, the solvent was removed under a gentle stream of argon and the residue was dissolved in $0.5 \mathrm{ml}$ of methanol/water 9:1 ( $\mathrm{vol} / \mathrm{vol})$. The oxysterols were thereafter analyzed as previously described (24), using $\left[{ }^{2} \mathrm{H}_{7}\right] 7 \beta$-hydroxycholesterol, 7-oxo- $\left[{ }^{2} \mathrm{H}_{7}\right]$ cholesterol and $\left[{ }^{2} \mathrm{H}_{7}\right]$ cholesterol-5,6-epoxide as internal standards. Vitamin $\mathrm{E}$ levels in serum were analyzed by high performance liquid chromatography (26). To assay BHT levels, $100 \mu \mathrm{l}$ aliquots of serum were extracted with $300 \mu \mathrm{l}$ hexane containing $90 \mathrm{ng} 2$, (3)-tert-butyl-4-hydroxyanisole as an internal standard. The solvent was evaporated under a gentle stream of nitrogen, and the extract was dissolved in $50 \mu$ l hexane and analyzed by capillary gas chromatography. The assay was linear for BHT levels $<8 \mathrm{mg} / \mathrm{ml}$.

Immunohistochemistry. Tissue samples from each aorta were snap frozen in liquid nitrogen and stored at $-70^{\circ} \mathrm{C}$. Air-dried, 4-5- $\mu \mathrm{m}$ thick cryostat sections were fixed in aceton. Endogenous peroxidase was blocked by incubating the sections in $0.3 \%$ aqueous hydrogen peroxide for $15 \mathrm{~min}$. The specimens were then rinsed in PBS, exposed to $10 \%$ normal goat serum for $30 \mathrm{~min}$, and incubated with the RAM 11 macrophage specific antibody, the HHF 35 muscle-specific $\alpha$-actin antibody (both antibodies were kindly provided by Dr. Allen Gown, University of Seattle, WA) and the L11/135 lymphocyte-specific antibody (kindly provided by Dr. Göran Hansson, University of Gothenburg, Gothenburg, Sweden) in a humidifying chamber for $24 \mathrm{~h}$ and rinsed twice in PBS. These antibodies have recently been demonstrated to have the capacity to stain their respective cells in rabbits (27). Controls included antibodies to irrelevant antigens, as well as omission of the primary antibody. The sections were incubated with peroxidase-labeled anti-mouse or anti-rabbit IgG for $45 \mathrm{~min}$, rinsed, and exposed to 0.3\% peroxide/diaminobenzidine (Becton Dickinson, Mountain View, CA), followed by $0.5 \%$ copper sulphate. The specimens were then rinsed, stained with hematoxylin, and mounted on glass slides.

Analysis of intimal thickness and cell density. Cryostat sections were obtained from three different locations of the abdominal aorta of each rabbit and stained using the modified Verhoff's van Gieson stain for elastin (Sigma Diagnostics, St. Louis, MO). Intimal thickness was analyzed using an image analysis system (Optilab; Graftek, MeudonLa-Foret, France) on a Macintosh IIci computer. Measurements of intimal thickness was performed with $100-\mu \mathrm{m}$ intervals along the complete section and the mean intimal thickness for each section was calculated. An average of 70 measurements were made on each section. Since many sections contained focal lesions in parts of the section, intimal thickness could vary considerably within the same cross section of the vessel. A mean intimal thickness for the section was calculated by dividing the sum of all measurements with the number of measurements performed. The mean intimal thickness for each animal was determined by calculating the mean intimal thickness of all three sections analyzed. The minimal and maximal thickness observed in each animal was also determined. Intimal cell numbers were calculated and expressed both as number of cells per millimeter of intima (the total number of cells in the intima were counted and divided with the length of the cut open cross section of the vessel) to estimate the total number of cells in the intima, as well as cell number per square millimeter of intima to estimate intimal cell density.

Electron microscopy. Tissue samples intended for electron microscopy were fixed in $3 \%$ glutaraldehyde in $0.1 \mathrm{M}$ cacodylate buffer containing $0.1 \mathrm{M}$ sucrose, rinsed, and postfixed in $1 \% \mathrm{OsO}_{4}$ for $4 \mathrm{~h}$. They were then stained with $0.5 \%$ uranyl acetate for $1 \mathrm{~h}$, dehydrated in aceton, and embedded in resin (Westopal, Geneva, Switzerland). Thin sections were cut on an ultrotome (LKB Instruments Inc., Bromma, Sweden) and examined under an electron microscope (model 400; Philips, Eindhoven, The Netherlands).

Statistical methods. Student's $t$ test for unpaired samples was used to detect differences between groups.

\section{Results}

Throughout the study, no significant changes in the serum lipid pattern were seen between the animals fed standard chow supplemented with $0.25 \%$ cholesterol and those given standard chow supplemented with $0.25 \%$ cholesterol and $1 \%$ BHT ( Table I). The initial serum cholesterol values were $1.19 \pm 0.45$ $\mathrm{mmol} /$ liter and $1.25 \pm 0.27 \mathrm{mmol} / \mathrm{liter}$ in the control and BHT-treated groups, respectively. At the time of the balloon injury, the cholesterol values had increased to $6.28 \pm 5.80$ $\mathrm{mmol} /$ liter in the control group and to $7.50 \pm 4.54 \mathrm{mmol} /$ liter in the BHT-treated group. Cholesterol values continued to increase during the subsequent $3 \mathrm{wk}$ to $7.78 \pm 5.06 \mathrm{mmol} /$ liter in the control group and to $11.31 \pm 6.00 \mathrm{mmol} /$ liter in the BHTtreated group. These levels were clearly lower than observed in our earlier study (23), in which the diet was supplemented with a much higher cholesterol content. Serum triglyceride levels and weight remained stable throughout the study.

Light microscopic analysis of aortas from rabbits in the group fed only cholesterol demonstrated abundant focal intimal fibromuscular lesions (Fig. 1, $a, c, e$, and $g$ ). These lesions were frequently thicker than the underlying media. Areas of diffuse intimal thickening were present between the lesions. No areas completely lacking an intimal thickening could be detected in any of these animals. In the BHT-treated rabbits, 
Table I. Plasma Cholesterol and Triglyceride Levels in Rabbits Treated with Diet Containing $0.25 \%$ Cholesterol or $0.25 \%$ Cholesterol/1\% BHT

\begin{tabular}{lccc}
\hline \multicolumn{1}{c}{ Variable } & $\begin{array}{c}\text { Cholesterol } \\
(n=8) \\
\text { mean } \pm \text { SEM }\end{array}$ & $\begin{array}{c}\text { Cholesterol/BHT } \\
(n=8) \\
\text { mean } \pm \text { SEM }\end{array}$ & $P$ \\
\hline Plasma cholesterol (mmol/liter) & & & \\
Start of treatment & $1.19 \pm 0.16$ & $1.25 \pm 0.10$ & NS \\
3 wk of treatment & $6.28 \pm 2.05$ & $7.50 \pm 1.61$ & NS \\
6 wk of treatment & $7.78 \pm 1.79$ & $11.31 \pm 2.12$ & NS \\
Total exposure & $33.39 \pm 10.60$ & $41.35 \pm 7.83$ & NS \\
Plasma triglycerides (mmol/liter) & & & \\
Start of treatment & $0.58 \pm 0.08$ & $0.52 \pm 0.06$ & NS \\
3 wk of treatment & $0.56 \pm 0.11$ & $0.56 \pm 0.13$ & NS \\
6 wk of treatment & $0.65 \pm 0.14$ & $0.51 \pm 0.12$ & NS \\
Weight (kg) & & & \\
Start of treatment & $3.45 \pm 0.09$ & $3.41 \pm 0.11$ & NS \\
3 wk of treatment & $3.45 \pm 0.16$ & $3.31 \pm 0.11$ & NS \\
6 wk of treatment & $3.42 \pm 0.20$ & $3.34 \pm 0.11$ & NS \\
& & & \\
\hline
\end{tabular}

occasional lesions were also observed, but these were never thicker than the underlying media. In addition, a diffuse intimal thickening was present in large parts of the aorta (Fig. 1, $d$, $f$, and $h$ ). These thickenings were usually not more than a few cell layers. The mean intimal thickness of the BHT/cholesterol-treated rabbits was only one fourth of that of the cholesterol-fed animals (Table II). Also, as seen in Fig. 2, both the average minimal and maximal intimal thickness were significantly lower in cholesterol / BHT-treated rabbits. In three of the BHT-treated animals, the aortas completely lacked intimal thickening (Fig. $1 b$ ). Intimas of BHT-fed animals contained about half as many cells per millimeter as that of cholesterolfed animals. In spite of that, the number of cells per square millimeter of intima was lower in cholesterol-fed animals ( Table II), possibly suggesting that the BHT treatment inhibited not only cell replication and / or migration, but also secretion of extracellular matrix components. No significant difference in intimal thickening between the BHT/cholesterol-fed and the cholesterol-fed rabbits was found after $3 \mathrm{wk}$ of treatment just before balloon injury $(4.75 \pm 0.16 \mu \mathrm{m}$ vs $6.63 \pm 1.05 \mu \mathrm{m})$.

The possibility to use cell-specific antibodies to identify SMC, macrophages and lymphocytes in rabbit atherosclerotic lesions was recently demonstrated by Hansson and co-workers (27). In the present study, we therefore used the HHF $35 \alpha$-actin antibody to identify SMC, the RAM 11 antibody to identify macrophages and the L11/135 antibody for T lymphocytes. Positive staining for $\alpha$-actin was found in the intima and media of both cholesterol-fed and BHT-treated animals, whereas no or only weak staining was present in the adventitia (Fig. 1, $c$ and $d$ ). The fibromuscular lesions showed a uniform stain for $\alpha$-actin. A persistent finding in both groups was that the intima showed a stronger staining than the media for $\alpha$-actin. The intimal lesions in cholesterol-fed animals also stained uniformly with the macrophage RAM 11 antibody (Fig. $1 e$ ). A clear but less intense staining with the RAM 11 antibody was observed in diffuse intimal thickenings in the BHT-treated group (Fig. $1 f$ ). These intimas were usually only stained close to the internal elastic lamina, whereas the area close to the surface appeared to contain few macrophages. Occasional cells showing positive staining for the $\mathrm{L} 11$ / $135 \mathrm{~T}$ lymphocyte antibody were present in intimas of cholesterol-fed rabbits (Fig. 1 $g$ ), whereas no such cells could be identified in BHT-treated animals (Fig. $1 h$ ).

Electron microscopic analysis of the aortic fibromuscular lesions in cholesterol-fed rabbits demonstrated that the lesions were rich in cells. Many of these cells had an ultrastructure of synthetic SMC with a cytoplasm rich in synthetic organelles, such as endoplasmatic reticulum and Golgi complexes. The cells frequently contained a few peripheral lipid droplets (Fig. 2 a). In the central region of the lesion and close to the internal elastic lamina, macrophage-like foam cells were present (Fig. 3 $b$ ). The connective tissue of the lesions was very loose and did not contain the distinct collagen bundles or elastin fibres found in the underlying media. In some areas, the lesions were covered by organized thrombus. The ultrastructure of aortas from BHT-treated animals was similar to that of the cholesterol-fed animals, although macrophage-like foam cells were less frequent in the BHT-treated animals, and the SMC frequently contained numerous lipid droplets (Fig. $3 c$ ). The intima of BHT-treated animals also appeared to be more densely populated than the intima of control animals. The media of the BHT-treated animals were well organized and contained distinct layers of SMC. On the contrary, in cholesterol-fed animals, the parts of the media that were located beneath the focal lesions contained few and irregularly distributed cells.

Analysis of cholesterol autooxidation products in the aorta, as well as determinations of serum vitamin $E$ levels were performed to evaluate the effect of BHT treatment on lipid oxidation. There was no significant difference in serum vitamin $E$ levels between the rabbits in the control group and those in the BHT-treated group $(12.8 \pm 7.8 \mu \mathrm{mol} /$ liter vs $14.2 \pm 5.7 \mu \mathrm{mol} /$ liter). However, analysis of the relative amount of oxidized cholesterol derivatives in aorta demonstrated increased amounts of 7-oxo-cholesterol, cholesterol 5,6-epoxide and 7 $\beta$ hydroxycholesterol in cholesterol-fed animals as compared to BHT-treated animals (Table III). In four of the cholesterol/ BHT-treated animals, plasma BHT levels were lower than the lowest standard $(0.20 \mathrm{mg} / \mathrm{liter})$. In the other four animals, the levels ranged between 0.21 and $1.35 \mathrm{mg} /$ liter (mean level $=0.55 \mathrm{mg}$ /liter). These levels were lower than in our previous study (23), compatible with the present shorter treatment period.

\section{Discussion}

In the present study, a moderate dietary-induced hypercholesterolemia in combination with a vascular trauma resulted in development of focal fibromuscular lesions containing SMC, macrophages, and occasional $\mathrm{T}$ lymphocytes. In accordance with several previous studies (28-30), ultrastructural analysis showed that the lesions consisted of contractile SMC containing some lipid droplets and macrophage-like cells loaded with varying amounts of lipids. The matrix of the lesions was loose and appeared to consist mainly of glycosaminoglycans and collagen. The media underlying the lesions contained few cells. The role of lipid oxidation in development of the above lesions was investigated by supplementing the diet of half of the rabbits with $1 \%$ BHT. This treatment has earlier demonstrated to decrease serum levels of cholesterol autooxidation products and the development of atherosclerosis in spite of increased total 

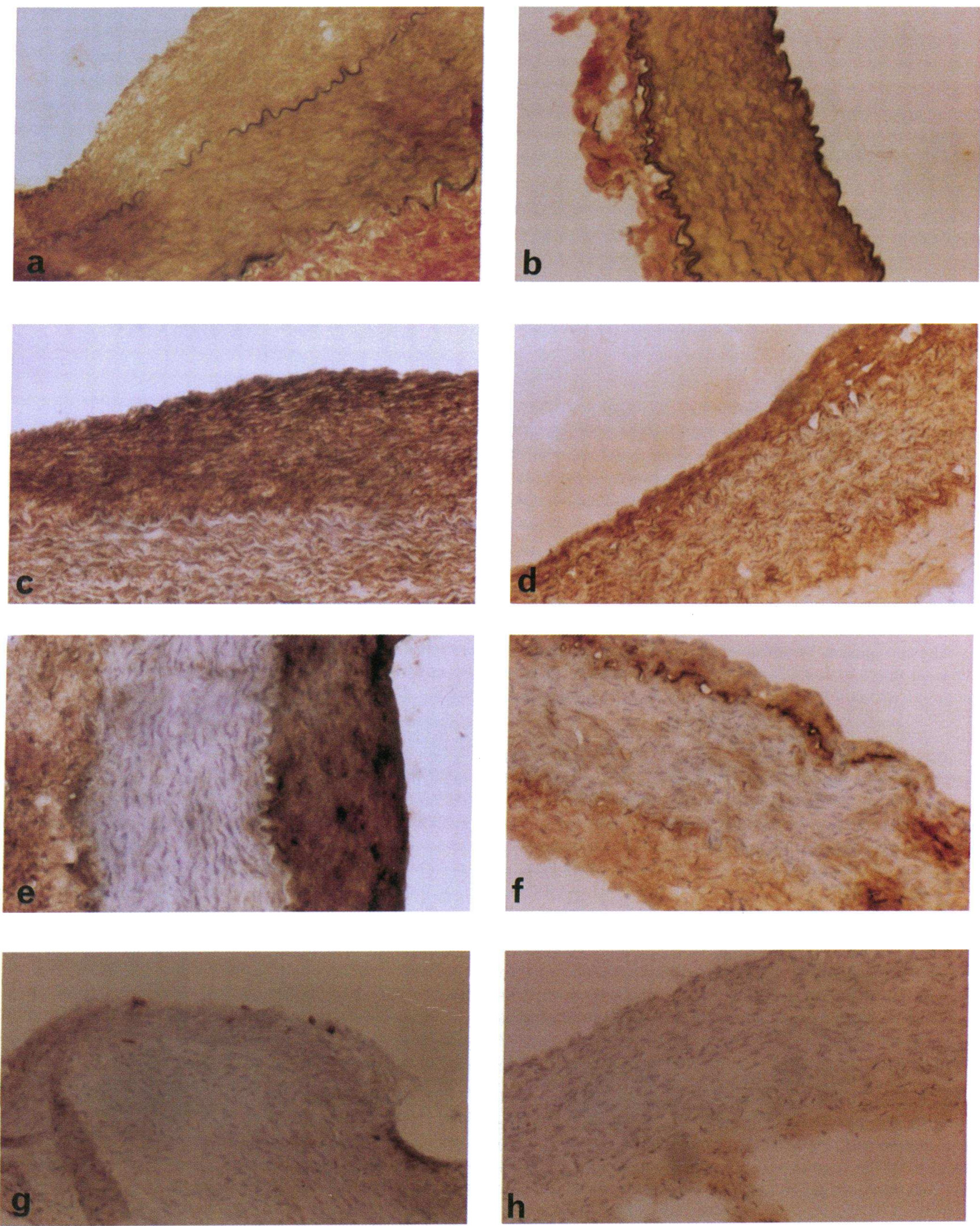

Figure 1. Elastin staining and cell-specific immunoreactivity of aortas of hypercholesterolemic control (left panel) and hypercholesterolemic BHT-treated rabbits (right panel). The micrographs show sections stained with the modified Verhoff's van Gieson stain for elastin $(a$ and $b$ ), the muscle-specific $\alpha$-actin antibody HHF $35(c$ and $d)$, the macrophage-specific antibody RAM $11(e$ and $f$ ), and the lymphocyte-specific antibody L11/135 $(g$ and $h)$. The immunostains were counterstained with hematoxylin. $\times 140$. 
Table II. Intimal Thickness, Cell Number, and Cell Density in Rabbits Treated with Diet Containing 0.25\% Cholesterol or $0.25 \%$ Cholesterol/1\% BHT

\begin{tabular}{cccc}
\hline & $\begin{array}{c}\text { Cholesterol } \\
(n=8) \\
\text { mean } \pm \text { SEM }\end{array}$ & $\begin{array}{c}\text { Cholesterol/BHT } \\
(n=8) \\
\text { mean } \pm \text { SEM }\end{array}$ & $P$ \\
\hline $\begin{array}{l}\text { Intimal thickness }(\mu \mathrm{m}) \\
\begin{array}{c}\text { Cell number } \times 10^{3} / \\
\text { mm intima }\end{array}\end{array}$ & $85.5 \pm 11.2$ & $20.0 \pm 3.0$ & $P<0.0001$ \\
$\begin{array}{c}\text { Cell number } \times 10^{3} / \\
\mathrm{mm}^{2} \text { intima }\end{array}$ & $301.5 \pm 17.9$ & $154.5 \pm 21.6$ & $P<0.001$ \\
\hline
\end{tabular}

serum cholesterol levels (23). The addition of BHT was found to significantly inhibit the formation of intimal lesions after balloon injury. The mean intimal thickness of the cholesterol/ BHT-treated rabbits was thus only $\sim 25 \%$ of that in the cholesterol-fed rabbits. The intima of BHT-treated rabbits also contained significantly fewer cells per millimeter than the intima of cholesterol-fed animals. In addition, the mean number of cells per square millimeter of intima was higher in the BHTtreated group, possibly suggesting that BHT inhibited not only the increase in intimal cell number, but also the amount of extracellular matrix secreted by the cells. The immunohistological analysis showed that the intima of BHT-treated rabbits contained fewer macrophages and $\mathrm{T}$ lymphocytes than in controls, but otherwise, there were no major morphological differences between intimas of the two groups.

The mechanism responsible for the inhibitory effect of BHT on development of intimal lesions demonstrated here remains to be clarified. Although it seems likely that the protective effect of BHT is mediated by effects on oxidative modification on plasma lipoproteins, other mechanisms cannot be excluded at the present stage of knowledge. It might be argued that BHT could affect oxidation of lipids in cells in the vessel media damaged through balloon injury. Although we at present can not exclude this possibility, we have recently found that BHT increases the resistance of LDL to oxidative modification in vitro (AL-Shurbaji, A., A. Freyschuss, L. Sisfontes, I. Björkhem, P. Henriksson, L. Berglund, unpublished observation). However, further studies on the effect of BHT on the vessel response to balloon injury during normolipidemic conditions are needed to address this issue. Studies performed by Faggiotto and co-workers on hypercholesterolemic primates suggest that the development of fibromuscular lesions is preceded by an intimal accumulation of lipid-laden macrophages (28). Subsequently, SMC migrate from the media into the intima, where they proliferate and secrete extracellular matrix components leading to the formation of fibromuscular lesions (29). This finding is consistent with the contention that uptake of oxidized LDL in intimal macrophages may play a role in the recruitment and activation of SMC. Attempts to demonstrate this have given somewhat conflicting results in different models. In a recent study, Malden and co-workers investigated the possibility that macrophages exposed to oxidized LDL may be stimulated to synthesize and secrete PDGF, a potent activator of SMC migration and growth. They found that oxidized LDL inhibited both basal and endotoxin-induced expression of PDGF-B chains in these cells (20). Accordingly, it has been demonstrated that oxidized LDL suppresses the expression of
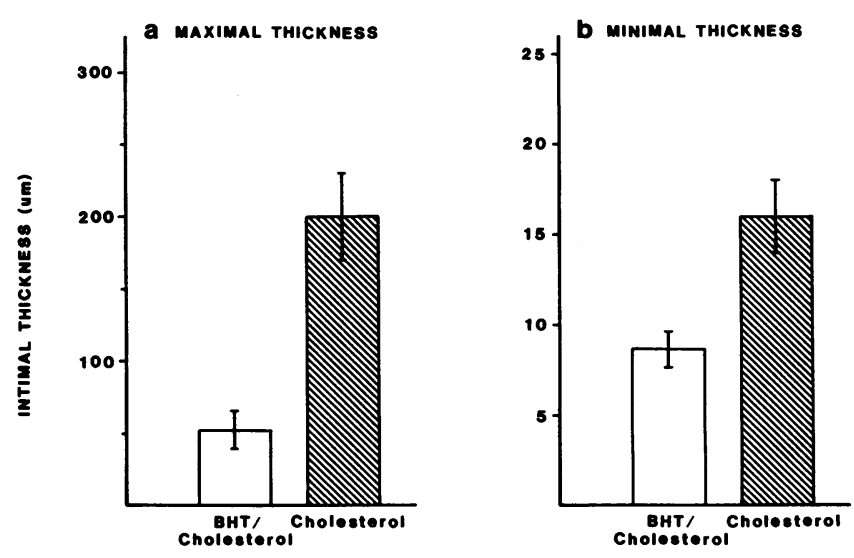

Figure 2. Mean maximal (a) and minimal (b) intimal thickness in cholesterol- and BHT/ cholesterol-fed rabbits. The numbers are mean values \pm SEM from eight animals in each group and the measurements were performed as detailed in the text.

TNF- $\alpha$ mRNA in murine peritoneal macrophages (31), and that LDL modified by acetylation inhibits the release of PDGF from cultured endothelial cells (32). In contrast, others have found that minimally modified LDL increases endothelial synthesis of macrophage colony stimulating factor (33), and that copper-oxidized LDL enhances the secretion of IL-1 from human monocytes (10). In a recent study, we also demonstrated that cultured human SMC exposed to oxidized LDL both increased their basal rate of DNA synthesis and became more sensitive to stimulation with exogenous PDGF. This effect was accompanied by an increased release of PDGF A-A homodimers from the cells and by an increased cell surface expression of PDGF receptors (19). The apparent conflicting results obtained with oxidized LDL may reflect differences in degree of oxidative modification. This emphasizes the need for more exact methods to characterize the degree of modification and the structural changes in the LDL preparations used. However, the finding in the present study that the aortas of BHT-treated rabbits contained decreased amounts of cholesterol autooxidation products supports the contention that the inhibitory effect of BHT on the intimal thickening could be caused by inhibition of lipid oxidation. In a recent study, Rosenfeld et al., using a similar protocol with balloon injury and cholesterol feeding, demonstrated an accumulation in rabbit aorta of epitopes characteristic of oxidized LDL (34). This finding strongly suggests that LDL does undergo oxidation during the present conditions and further underscores the conclusion that BHT exerts its antiatherogenic effect as an antioxidant. As discussed above, there are several potential mechanisms by which an inhibition of oxidative modification of LDL may interfere with the development of fibromuscular lesions. It is thus possible that the effect of BHT on development of intimal lesions may partly be caused by inhibition of intimal leukocyte recruitment and activation. This was supported by our finding that the intima of BHT-treated rabbits contained less macrophages and T lymphocytes. Yet other possibilities are that BHT might interfere with release of growth factors from intimal cells induced by oxidized LDL, or affect the tissue response to the cytotoxic effect of oxidized LDL during long time exposure. Also, oxidized LDL is chemotactic for monocytes (35). Thus, a lower degree of oxidative modification might contribute to the reduced number of intimal leukocytes in the presence of BHT. 

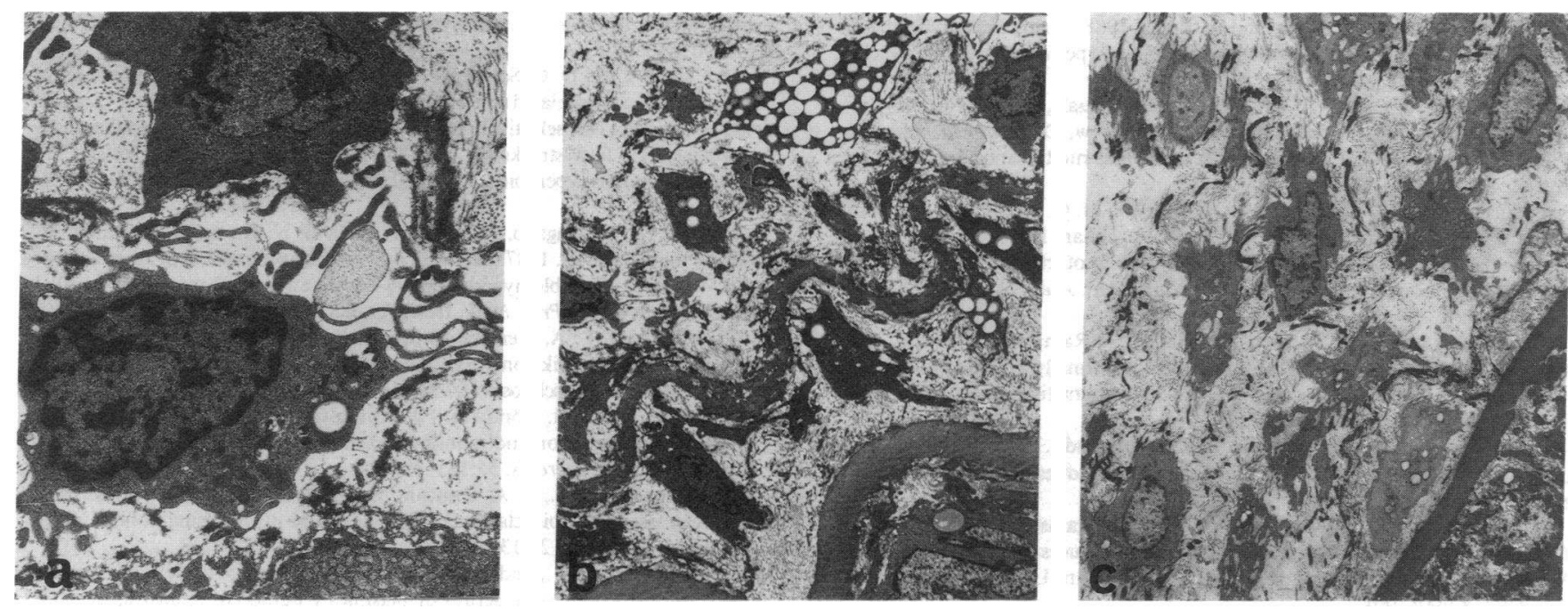

Figure 3. Electron micrographs of the intima from a control rabbit showing $(a)$ SMC containing synthetic organelles and some lipid droplets $(\times 8,000),(b)$ a section of the internal elastic lamina, SMC, and a foam cell $(\times 2,400)$, and $(c)$ the intima of a BHT-treated rabbit showing densely packed SMC in the vicinity of the internal elastic lamina $(\times 2,400)$.

To further evaluate these possibilities, detailed analysis is required of the effect of antioxidant treatment on intimal growth factor production during the early period after balloon injury. However, whatever the mechanisms, the results clearly demonstrate that the presence of the antioxidant BHT modified the arterial response to injury in moderately hypercholesterolemic rabbits.

Plasma lipid values in the present study showed no significant difference between cholesterol/BHT- and cholesterol-fed rabbits, although there was a tendency to higher cholesterol exposures and final plasma cholesterol levels in the BHT group. In our previous study, using a higher cholesterol load, the circulating levels of cholesterol were significantly higher in the BHT treated group (23). There was also a very pronounced increase in plasma triglycerides in the BHT-treated rabbits. This may be of relevance, since the fatty acid pattern in the plasma triglycerides could be of importance during oxidative modification. However, in the present study, no difference in plasma triglycerides was seen between the two groups. The implication of this difference between the two models and the possible role of the triglyceride increase requires further studies.

Table III. Relative Amounts of Autooxidation Products of Cholesterol in Aortas of Rabbits Treated with Diet Containing $0.25 \%$ Cholesterol or 0.25\% Cholesterol/1\% BHT

\begin{tabular}{|c|c|c|c|}
\hline Variable & $\begin{array}{c}\text { Cholesterol } \\
(n=8) \\
\text { mean } \pm \text { SEM }\end{array}$ & $\begin{array}{c}\text { Cholesterol/BHT } \\
(n=8) \\
\text { mean } \pm \text { SEM }\end{array}$ & $P$ \\
\hline $\begin{array}{l}\text { 7-oxocholesterol } \\
\text { (ng/ug cholesterol) }\end{array}$ & $1.02 \pm 0.10$ & $0.30 \pm 0.01$ & $P<0.0001$ \\
\hline $\begin{array}{l}\text { Cholesterol 5,6 epoxide* } \\
\text { (ng/ } \mu \mathrm{g} \text { cholesterol) } \\
7 \beta \text {-hydroxycholesterol }\end{array}$ & $0.63 \pm 0.06$ & $0.26 \pm 0.01$ & $P<0.001$ \\
\hline$(\mathrm{ng} / \mu \mathrm{g}$ cholesterol) & $0.44 \pm 0.02$ & $0.21 \pm 0.01$ & $P<0.001$ \\
\hline
\end{tabular}

* The figure represents the sum of the $5 \alpha$ - and the $5 \beta$-epimers.
To our knowledge, the present study is the first attempt to study the effect of antioxidants in a tissue injury model during lipid exposure. The results support the hypothesis that an oxidative modification of LDL plays an important role in atherogenesis. They also indicate that lipid oxidation products may enhance intimal SMC proliferation and/or migration and extracellular matrix production after arterial injury. Furthermore, the results are consistent with a possible therapeutic role of antioxidants; e.g., in connection with the process of restenosis after angioplasty of coronary arteries in humans.

\section{Acknowledgments}

We wish to express our gratitude to Ms. Gunvor Nilsson, Ms. Britt Dahlgren, and Ms. Marina Nyborg for excellent technical assistance.

This work was supported by Swedish Medical Research Council (204, 3041, and 8311), the Knut and Alice Wallenberg Foundation, the King Gustaf Vth and Queen Victoria's Foundation, the Swedish Heart and Lung Foundation, the Foundation for Old Servants, King Gustaf V 80th Birthday Fund, the Swedish Society of Medicine, the Nanna Swartz Fund, Axelsson-Johnsson Foundation, and the Swedish Margarine Industry's Association for Nutritional Physiological Research.

Note added in proof. After acceptance of our paper, Ferns et al. have published a study using a similar approach (1992. Proc. Natl. Acad. Sci. USA. 89:11312-11316). In accordance with our results, they found that the antioxidant probucol treatment of hypercholesterolaemic rabbits reduced intimal size, intima/media thickness ratio, and inhibited neointimal macrophage accumulation after balloon injury. Unlike the present study with BHT, treatment with probucol also resulted in a $30 \%$ reduction of serum cholesterol levels.

\section{References}

1. Steinberg, D., S. Parthasarathy, T. E. Carew, J. C. Khoo, and J. L. Witztum. 1989. Beyond cholesterol. Modification of low density lipoprotein that increase its atherogenicity. N. Engl. J. Med. 320:915-925.

2. Brown, M. S., S. K. Basu, J. R. Falck, Y. K. Ho, and J. L. Goldstein. 1980. The scavenger cell pathway for lipoprotein degradation. Specificity of the binding site that mediates the uptake of negatively-charged LDL by macrophages. $J$. Supramol. Struct. 13:67-81.

3. Steinberg, D., and J. L. Witztum. 1991. Role of oxidized low density lipoprotein in atherogenesis. J. Clin. Invest. 88:1785-1792. 
4. Haberland, M. E., D. Fong, and L. Cheng. 1988. Malondialdehyde-altered protein occurs in atheroma of Watanabe heritable hyperlipemic rabbits. Science (Wash. DC). 241:215-218.

5. Palinsky, W., M. E. Rosenfeld, S. Ylä-Herttuala, G. C. Gurtner, S. S. Sucher, S. W. Butler, S. Parthasarathy, T. E. Carew, D. Steinberg, and J. L. Witztum. 1989. Low density lipoprotein undergoes modification in vivo. Proc. Natl. Acad. Sci. USA. 86:1372-1376.

6. Cushing, S. D., J. A. Berliner, A. J. Valente, M. C. Ternito, M. Navab, F. Parhami, R. Gerity, C. J. Schwartz, and A. M. Fogelman. 1990. Minimally modified low density lipoprotein induces monocyte chemotactic protein 1 in human endothelial cells and smooth muscle cells. Proc. Natl. Acad. Sci. USA. 87:51345138.

7. Berliner, J. A., M. C. Territo, A. Sevanian, S. Ramin, J. A. Kim, B. Bamshad, M. Esterson, and A. F. Fogelman. 1990. Minimally modified low density lipoprotein stimulates monocyte endothelial interactions. J. Clin. Invest. 85:1260-1266.

8. Frostegård, J., A. Haegerstrand, M. Gidlund, and J. Nilsson. 1991. Biologically modified low density lipoprotein increases the adhesive properties of endothelial cells. Atherosclerosis. 90:119-126.

9. Frostegård, J., J. Nilsson, A. Haegerstrand, A. Hamsten, H. Wigzell, and M. Gidlund. 1990. Oxidized low density lipoprotein induces differentiation and adhesion of human monocytes and the monocytic cell line U 937. Proc. Natl. Acad. Sci. USA. 87:904-908.

10. Frostegård, J., R. Wu, R. Giscombe, G. Holm, A.-K. Lefvert, and J. Nilsson. 1992. Induction of T cell activation by oxidized low density lipoprotein. Arterioscler. Thromb. 12:461-467.

11. Ross, R. 1986. The pathogenesis of atherosclerosis: an update. N. Engl. J. Med. 314:488-500.

12. Nilsson, J. 1986. Growth factors and the pathogenesis of atherosclerosis. Atherosclerosis. 62:185-199.

13. DiCorleto, P. E., and D. F. Bowen-Pope. 1983. Cultured endothelial cells produce a platelet-derived growth factor-like protein. Proc. Natl. Acad. Sci. USA. 80:1919-1923.

14. Nilsson, J., M. Sjölund, L. Palmberg, J. Thyberg, and C.-H. Heldin. 1985 Arterial smooth muscle cells in primary culture produce a platelet-derived growth factor-like protein. Proc. Natl. Acad. Sci. USA. 82:4418-4422.

15. Shimokado, K., E. W. Raines, D. K. Madtes, T. B. Barrett, E. P. Benditt, and R. Ross. 1985. A significant part of macrophage-derived growth factor consists of at least two forms of PDGF. Cell. 43:277-286.

16. Barrett, T. B., and E. P. Benditt. 1987. sis ( platelet-derived growth factor B chain) gene transcript levels are elevated in human atherosclerotic lesions compared to normal artery. Proc. Natl. Acad. Sci. USA. 84:1099-1 103.

17. Wilcox, J. N., K. M. Smith, L. T. Williams, S. M. Schwartz, and D. Gordon. 1988. Platelet-derived growth factor mRNA detection in human atherosclerotic plaques by in situ hybridization. J. Clin. Invest. 82:1134-1143.

18. Ross, R., J. Masuda, E. W. Raines, A. M. Gown, S. Katsuda, M. Sasahana L. T. Malden, H. Masuko, and H. Sato. 1990. Localization of PDGF-B protein in macrophages in all phases of atherogenesis. Science (Wash. DC). 248:10091012.

19. Stiko-Rahm, A., A. Hultgårdh-Nilsson, J. Rengström, A. Hamsten, and J. Nilsson. 1992. Oxidized and native LDL enhances production of PDGF AA and the surface expression of PDGF receptors in cultured human arterial smooth muscle cells. Arterioscler. Thromb. 12:1099-1109.

20. Malden, L. T., A. Chait, E. W. Raines, and R. Ross. 1991. The influence of oxidatively modified low density lipoproteins on expression of platelet derived growth factor in human monocyte-derived macrophages. J. Biol. Chem. 266:13901-13907.

21. Carew, T. E., D. C. Schwenke, and D. Steinberg. 1987. Antiatherogenic effects of probucol unrelated to its hypocholesterolemic effect: evidence that antioxidants in vivo can selectively inhibit low density lipoprotein degradation in macrophage-rich fatty streaks and slow the progression of atherosclerosis in the Watanabe heritable hyperlipidemic (WHHL) rabbit. Proc. Natl. Acad. Sci. USA. 84:7725-7729.

22. Kita, T., Y. Nagano, M. Yokode, K. Ishii, N. Kume, A. Ooshima, H. Yoshida, and C. Kawai. 1987. Probucol prevents the progression of atherosclerosis in Watanabe heritable hyperlipidemic rabbit, an animal model for familial hypercholesterolemia. Proc. Natl. Acad. Sci. USA. 84:5928-5931.

23. Bjorkhem, I., A. Henriksson-Freyschuss, O. Breuer, U. Diczfalusy, L. Berglund, and P. Henriksson. 1991. The antioxidant butylated hydroxytoluene protects against atherosclerosis. Arteroscler. Thromb. 11:15-22.

24. Breuer, O., and I. Björkhem. 1990. Simultaneous quantification of several cholesterol autooxidation and monohydroxylation products by isotope-dilution mass spectrometry. Steroids. 55:185-192.

25. Kaluzny, M. A., L. A. Duncan, M. V. Merritt, and D. E. Epps. 1985. Rapid separation of lipid classes in high yield and purity using bonded phase columns. J. Lipid Res. 26:135-140.

26. Catignani, G. L., and J. G. Bieri. 1983. Simultaneous determination of retinol and $\alpha$-tocopherol in serum or plasma by liquid chromatography. Clin. Chem. 29:708-712.

27. Hansson, G. K., P. S. Seifert, G. Olsson, and G. Bondjers. 1991. Immunohistochemical detection of macrophages and $T$ lymphocytes in atherosclerotic lesions of cholesterol-fed rabbits. Arterioscler. Thromb. 11:745-750.

28. Faggiotto, A., R. Ross, and L. Harker. 1984. Studies of hypercholesterolemia in the nonhuman primate. I. Changes that lead to fatty streak formation. Arteriosclerosis. 4:323-340.

29. Faggiotto, A., and R. Ross. 1984. Studies of hypercholesterolemia in the nonhuman primate. II. Fatty streak conversion to fibrous plaque. Arteriosclero sis. 4:341-356.

30. Ferns, G. A. A., A. L. Stewart-Lee, and E. E. Änggård. 1992. Arterial response to mechanical injury: balloon catheter de-endothelialization. Atheroscle rosis. 92:89-104.

31. Hamilton, T. A., G. P. Ma, and G. M. Chisholm. 1990. Oxidized low density lipoprotein suppresses the expression of tumor necrosis factor alpha mRNA in stimulated murine peritoneal macrophages. J. Immunol. 144:23432350.

32. Fox, P. L., and P. E. DiCorleto. 1986. Modified low density lipoproteins suppress production of a platelet-derived growth factor-like protein by cultured endothelial cells. Proc. Natl. Acad. Sci. USA. 83:4774-4778.

33. Rajavashisth, T. B., A. Andalibi, M. C. Territo, J. A. Berliner, M. Navab, A. M. Fogelman, and A. J. Lusis. 1990. Induction of endothelial cell expression of granulocyte and macrophage colony stimulating factor by modified low density lipoproteins. Nature (Lond.). 344:254-257.

34. Rosenfeld, M. E., J. C. Khoo, E. Miller, S. Parthasarathy, W. Palinski, and J. L. Witztum. 1991. Macrophage-derived foam cells freshly isolated from rabbit atherosclerotic lesions degrade modified lipoproteins, promote oxidation of low density lipoproteins, and contain oxidation-specific lipid-protein adducts. $J$. Clin. Invest. 87:90-99.

35. Quinn, M. T., S. Parthasarathy, L. G. Fong, and D. Steinberg. 1987. Oxidatively modified low density lipoproteins: a potential role in recruitment and retention of monocyte/macrophages during atherogenesis. Proc. Natl. Acad. Sci. USA. 84:2995-2998. 